\title{
PELATIHAN SUSTAINED SILENT READING (SSR) UNTUK GURU DI SDN MEKARWANGI 1 DAN 2 KECAMATAN SAKETI KABUPATEN PANDEGLANG
}

\author{
Erna Irawati * \\ Universitas Mathla'ul Anwar \\ Banten
}

Veny Agustini Prianggita Universitas Mathla'ul Anwar Banten

\section{Nenden Suciyati Sartika Universitas Mathla'ul Anwar Banten}

\section{Susti Rahmah Yulita S.}

Universitas Mathla'ul Anwar Banten

\begin{abstract}
SUSTAINED SILENT READING (SSR) TRAINING FOR TEACHERS IN SDN MEKARWANGI 1 AND 2 SAKETI DISTRICT PANDEGLANG REGENCY. Staff-training is one of eight principles that influences the success of Sustained Silent Reading (SSR) program. The eight principles of SSR program are access to book, book appeal, encourage to read, conducive environment, time to read, follow-up activity, non-accountability, and staff-training. This training facilitates the teachers in SDN Mekarwangi 1 and 2 to get the staff-training. The purpose of this training is to create an SSR program in those schools as a compulsory activity, read non-textbook reading for 15 minutes before class, which is obligated by government. Training was conducted a day in SDN Mekarwangi 1 and 2 through two steps: theoretical and practical material about SSR program. The result of the training is schools' commitment and readiness to implement SSR program. SDN Mekarwangi 1 supported by school library is ready to implement SSR program next week after training, while SDN Mekarwangi 2 initiates One Student One Book movement to create class library before implementing SSR program. SSR activity in these two schools is adjusted to students' condition thus in its implementation is combined with Read Aloud activity for lower class to keep motivation and the engagement of students' reading activity in this SSR program.
\end{abstract}

\footnotetext{
* Corresponding Author: Program Studi Pendidikan Bahasa Inggris Fakultas Keguruan dan Ilmu Pendidikan (FKIP) Universitas Mathla'ul Anwar Banten; Jalan Raya Labuan KM. 23 Saketi, Kabupaten Pandeglang, Banten 42273, Indonesia; Email: ernairakarim@gmail.com
}

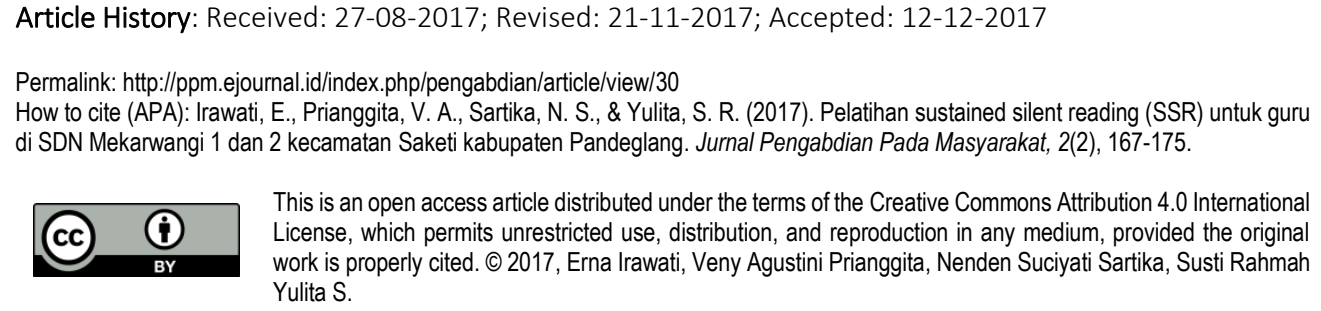

This is an open access article distributed under the terms of the Creative Commons Attribution 4.0 Internationa License, which permits unrestricted use, distribution, and reproduction in any medium, provided the original work is properly cited. @ 2017, Erna Irawati, Veny Agustini Prianggita, Nenden Suciyati Sartika, Susti Rahmah Yulita S.

\section{PENDAHULUAN}

Hampir seluruh negara maju memiliki budaya membaca yang sudah tertanam dengan baik. Data yang didapat dari Kantor Perpustakaan Nasional Republik Indonesia mengungkapkan bahwa penduduk negara maju membaca sekitar 20 buku setiap tahunnya. Sedangkan Indonesia setiap penduduknya paling banyak 
membaca tiga buku saja, itupun anak usia 0 hingga 10 tahun. Budaya membaca menjadi tolak ukur maju atau tidaknya suatu bangsa karena dengan membaca wawasan dan pengetahuan baru akan senantiasa bertambah.

Data statistik UNESCO pada tahun 2012 menyebutkan bahwa indeks minat baca di Indonesia baru mencapai 0,001 yang berarti hanya ada 1 orang saja yang tertarik untuk membaca dari 1000 orang Indonesia (Nafisah, 2016, p. 69). Pada tahun yang sama, dalam hal kemampuan membaca siswa, Programme for International Student Assessment (PISA) menempatkan negara kita di posisi ke 64 dari 65 negara yang diteliti (Ibda, 2017, p. 18). Data lain dari The United Nation Development Programme (UNDP) merilis angka melek huruf orang dewasa di Indonesia baru 65,5 persen, jauh apabila dibanding dengan negara tetangga Malaysia sebesar 86,4 persen (Inten, Permatasari, \& Mulyani, 2016, p. 70).

Mengapa fakta-fakta Indonesia tentang membaca di atas begitu memprihatinkan? Tentunya hal tersebut disebabkan oleh minimnya minat literasi di kalangan masyarakat kita. Salah satu faktornya, karena belum tertanamnya kebiasaan membaca sejak usia dini. Menanamkan kebiasaan agar menjadi suatu budaya memang harus sejak dini, sejak anak-anak masih di usia emasnya. Karena menanamkan budaya tertentu pada orang dewasa yang sudah terbentuk karakter diri ibarat meluruskan tulang yang bengkok, bisa namun sangat sulit.

Selain belum adanya kebiasaan membaca sejak dini, data yang didapat dari Badan Pusat Statistik (BPS) (Armadi et al, 2016) menunjukkan bahwa waktu menonton yang dihabiskan anak Indonesia setiap harinya mencapai 300 menit, presentase penduduk berumur 10 tahun ke atas yang menonton televisi terus meningkat setiap 3 tahun survey berulang dan di tahun 2012 mencapai 91,68\%. Sama halnya dengan Kantor Perpustakaan Nasional Republik Indonesia yang mencatat $90 \%$ penduduk Indonesia lebih menyukai menonton televisi daripada membaca. Menonton televisi memang tidak selamanya tidak baik, masih banyak tayangan televisi yang menyajikan nilai-nilai positif. Di Kanada, anak-anak menghabiskan hanya 60 menit waktunya untuk menonton setiap harinya.

Permasalahan dan fakta membaca di Indonesia memang masih menyedihkan, ditambah lagi ketersediaan buku bacaan yang murah dan terjangkau masih sangat minim. Namun pemerintah tidak pernah tinggal diam akan hal ini. Beberapa upaya telah dikerahkan dengan mencanangkan Gerakan Literasi Sekolah yang mengkampanyekan banyak program membaca di dalamnya, Gerakan Indonesia Membaca yang juga melibatkan banyak pihak sehingga pelaksanaannya merata 
tidak hanya di sekolah tetapi juga di masyarakat dengan dibentuknya taman bacaan masyarakat.

Permendikbud no. 23 tahun 2015 tentang penumbuhan budi pekerti mewajibkan menggunakan 15 menit sebelum hari pembelajaran untuk membaca buku selain buku pelajaran (setiap hari) yang dapat menemukenali dan mengembangkan potensi peserta didik secara utuh. Setiap sekolah oleh karenanya memiliki kewajiban untuk memfasilitasi peserta didik secara optimal yaitu dengan melaksanakan program membaca, salah satu program membaca yang diusulkan tim pengabdi adalah program membaca senyap berkelanjutan atau yang biasa dikenal dengan sebutan Sustained Silent Reading (SSR).

Ada banyak program membaca 15 menit yang serupa dengan kegiatan SSR seperti program DEAR (Drop Everything and Read), FVR (Free Voluntary Reading), DIRT (Daily Independent Reading Time), USSR (Uninterrupted Sustained Silent Reading), POWER (Provided Activities with Everyday Reading), SQUIRT (Sustained Quite Uninterrupted Reading Time), LTR (Love to Read), Recretional Reading, Independent Reading, Shared Reading, Read Aloud, dan masih banyak lagi. Program membaca ini dimaksudkan untuk membiasakan siswa membaca setiap hari sehingga budaya membaca dapat terbentuk.

Pilgreen (2000, p. 6) menyebutkan delapan (8) faktor yang mempengaruhi kesuksesan program SSR yaitu: akses buku, daya tarik buku, lingkungan yang kondusif, dorongan untuk membaca, non-akuntabilitas, ada batasan waktu, followup kegiatan, dan pelatihan staf. Akses buku atau ketersediaan buku menjadi prinsip pertama yang harus terpenuhi dalam SSR karena menurut Krashen (2013, p. 21) kondisi yang dibutuhkan untuk mendorong minat baca adalah akses buku atau bahan bacaan.

Gardiner (2005, p. 15) mendefinisikan Sustained Silent Reading sebagai waktu membaca senyap bersama di kelas atau di beberapa kelas di seantero sekolah. Siswa diperbolehkan memilih bacaannya sendiri dan membaca secara mandiri. SSR serentak dilaksanakan selama 15 menit di jam ke nol atau dilaksanakan sebelum kegiatan belajar mengajar dimulai. Dalam pelaksanaannya, SSR melewati beberapa tahapan sebagai berikut:

1) Siswa dipersilahkan memilih buku yang mereka minati atau buku yang mereka bawa dari rumah.

2) Guru menentukan waktu SSR dimulai dengan memberikan tanda.

3) Siswa dan guru membaca bersama selama 10 menit. 
4) Di menit ke sembilan guru memberikan reading log untuk merekam judul buku, nama pengarang, jumlah halaman yang dibaca dan amanat yang didapat dari buku yang dibaca.

5) Setelah 10 menit guru memberikan tanda waktu habis.

6) Guru mempersilahkan beberapa siswa menceritakan kembali apa yang dibaca di depan kelas.

7) Guru mempersilahkan siswa lain untuk menanggapi atau memberikan pertanyaan.

8) Guru menyimpulkan dan menutup kegiatan SSR.

SSR dalam penerapannya dapat disesuaikan dengan kebutuhan siswa untuk menjaga keterlibatan siswa dalam membaca, (Krashen, 2011, p. 9). Ada banyak variasi yang telah terbukti efektif dalam SSR. Marshal seperti dikutip Moser (2006, p. 34) menyertakan reading aloud yang membantu menciptakan motivasi dan semangat membaca, aktivitas mendengar cerita pendek; puisi; artikel surat kabar atau majalah; dan kutipan buku yang mencetuskan semangat bahwa pembaca perlu menggali bacaan mereka sendiri.

Salah satu SD Negeri di Desa Mekarwangi merupakan sekolah yang pernah mendapatkan bantuan berupa sumbangan buku-buku bacaan untuk perpustakaan dan pernah menerapkan program membaca 15 menit di pagi hari sebelum pembelajaran dimulai, yaitu SDN Mekarwangi 1. Berbeda dengan SDN Mekarwangi 1, SDN Mekarwangi 2 belum memiliki perpustakaan juga belum pernah melaksanakan program membaca.

Saat ini ketersediaan buku di perpustakaan SDN Mekarwangi 1 dan 2 sudah menipis, sebagian sudah koyak, sebagian hilang, namun tidak sedikit pula yang masih dapat digunakan. Perpustakaan di dua SD tersebut sudah lama tidak dimanfaatkan siswa. Program membaca sudah tidak berjalan lagi, pojok baca pun sudah tidak ada lagi.

Melihat fakta di lapangan yang seperti ini, kami masih melihat kemungkinan untuk dapat dihidupkan kembali program membaca yang pernah berjalan beberapa tahun lalu di SDN Mekarwangi 1, juga membentuk program membaca di SDN Mekarwangi 2. Oleh karenanya, penulis terilhami untuk melaksanakan salah satu Tri Dharma perguruan tinggi, yaitu pengabdian kepada masyarakat di Desa Mekarwangi dengan melaksanakan pelatihan Sustained Silent Reading (SSR) untuk guru di SDN Mekarwangi 1 dan 2 Kecamatan Saketi Kabupaten Pandeglang, Banten. 


\section{METODE PELAKSANAAN}

Pengabdian dilaksanakan dengan metode pelatihan penerapan program Sustained Silent Reading (SSR) bertempat di SDN Mekarwangi 1 dan 2 Kecamatan Saketi Kabupaten Pandeglang yang dilaksanakan selama 1 hari di hari yang sama pada Hari Senin 7 Agustus 2017. Tim pengabdi yang terdiri dari 4 orang dibagi menjadi 2 kelompok, 2 orang bertugas di SDN Mekarwangi 1 dan 2 orang bertugas di SDN Mekarwangi 2. Sasaran pelatihan ini adalah seluruh guru SDN Mekarwangi 1 dan 2 yang berjumlah 26, terdiri dari guru PNS dan Non-PNS.

Kegiatan pelatihan ini dilaksanakan melalui dua langkah, yaitu tahap pemberian materi secara teoritis dan praktis. Sesi pertama diberikan pengetahuan tentang fakta membaca di Indonesia dan berbagai kemungkinan kegiatan yang dapat meningkatkan minat baca sebagai solusinya. Sesi kedua diberikan pengetahuan praktis tentang bagaimana menerapkan program Sustained Silent Reading (SSR).

\section{HASIL DAN PEMBAHASAN}

Kegiatan pengabdian melalui pelatihan Sustained Silent Reading (SSR) ini disambut baik oleh guru-guru dan kepala sekolah sehingga kegiatan berjalan lancar. Pelatihan yang dalam rencana diikuti oleh 26 guru di dua SD, pada pelaksanaannya diikuti oleh 24 peserta termasuk mahasiswa, staf dan operator. Peserta terlihat antusias mengikuti seluruh kegiatan pelatihan dengan peran aktif mereka bertanya di sesi satu saat penyampaian materi dan terlibat diskusi di sesi dua saat praktek SSR.

Dilihat dari delapan prinsip SSR, SDN Mekarwangi 1 dan 2 memenuhi keseluruhan faktor yang mempengaruhi keberhasilan pelaksanaan program SSR dengan penjelasan sebagai berikut:

Pertama, akses buku telah terpenuhi oleh SDN Mekarwangi 1 dengan adanya perpustakaan sekolah, sedangkan SDN Mekarwangi 2 memiliki akses yang dekat dengan Taman Bacaan Masyarakat (TBM) sehingga siswa dapat meminjam buku bacaan pada TBM. Opsi lain untuk akses buku SDN Mekarwangi 2 adalah dengan menggagas gerakan One Student One Book (OSOB) untuk membentuk perpustakaan kelas. 
Kedua, daya tarik buku menjadi hal penting bagi pelaksanaan program SSR di tingkat Sekolah Dasar, buku-buku di perpustakaan SDN Mekarwangi walaupun lama tidak dimanfaatkan namun masih memiliki banyak buku bacaan yang menarik seperti buku cerita bergambar, ensiklopedi bergambar, dan buku lainnya yang juga dilengkapi gambar. Begitu pula dengan TBM yang walaupun ketersediaan bukunya lebih umum karena ditujukan untuk seluruh lapisan masyarakat, namun jumlah buku-buku menarik seperti buku cerita bergambar masih tersedia dalam jumlah yang besar.

Ketiga, lingkungan kondusif, letak SDN Mekarwangi 1 dan 2 berada jauh dari jalan raya sehingga kondisi kondusif mudah tercipta karena terbebas dari lalu lalang kendaraan bising.

Keempat, dorongan untuk membaca, kondisi siswa di waktu yang sama saat pelatihan SSR untuk guru juga mendapatkan sosialisai gemar membaca yang disampaikan oleh mahasiswa yang merupakan bagian dari tim pelatihan SSR. Beberapa video dan film pendek mengenai dampak gemar dan tidak gemar membaca diputar untuk merubah pola pikir siswa agar menjadikan membaca aktivitas penting untuk membuka jendela ilmu dan merubah dunia.

Kelima, non-akuntabilitas, kegiatan SSR menyertakan penggunaan reading log yang dimaksudkan untuk merekam jejak buku yang siswa baca secara kuantitas dan kualitasnya sehingga memudahkan guru untuk mengevaluasi sejauh mana keterkaitan antara jumlah dan jenis buku yang mereka baca dengan peningkatan kemampuan berbahasa mereka. Reading log tidak dimaksudkan untuk menilai siswa karena prinsip SSR non-akuntabilitas artinya tidak ada bentuk pertanggungjawaban siswa untuk melaporkan buku kemudian guru menilai dan siswa diberi skor, sehingga tidak ada siswa yang dianggap gagal jika mereka sekalipun salah menuliskan sumber yang mereka baca ataupun tidak pernah maju ke depan kelas untuk membagi isi cerita yang mereka baca.

Keenam, ada batasan waktu, SSR berlangsung 15 menit dengan aktivitas awal 10 menit membaca senyap dan 5 menit berdiskusi. Dilaksanakan di awal pembelajaran sebelum kelas dimulai.

Ketujuh, follow-up kegiatan, 5 menit terakhir merupakan kegiatan tindak lanjut dimana guru dan siswa berdiskusi menindaklanjuti apa yang telah dibaca dengan bertanya jawab dan mengambil kesimpulan dari apa yang dibaca.

Kedelapan, pelatihan staf, pelatihan SSR ini merupakan pelatihan staf bagi para guru SDN Mekarwangi 1 dan 2 yang bertugas menjalankan program SSR. 
Dalam pelaksanaan program SSR di tingkat Sekolah Dasar pada umumnya dapat dilaksanakan di semua kelas dengan tahapan yang sudah disebutkan dalam pendahuluan, namun dengan terlebih dahulu melihat kondisi siswa. Di SDN Mekarwangi 1 dan 2, setelah berdiskusi dengan guru kelas disana, tahapan ke 4 (reading $l o g$ ) bisa diberikan hanya untuk kelas atas. Sedangkan kelas bawah yang tidak memungkinkan penerapan SSR secara mandiri, maka dalam pelaksanaannya disertakan aktivitas Read Aloud atau Shared Reading dimana guru yang membacakan cerita lalu guru dan siswa bersama-sama berdiskusi mengenai cerita yang dibaca.

Di akhir sesi pelatihan, fasilitator mengambil komitmen dan kesiapan sekolah dalam pelaksanaan program SSR dan seluruh guru menyatakan kesediaannya untuk melaksanakan program SSR, yaitu membaca 15 menit di jam ke nol, dimulai di minggu berikutnya untuk SDN Mekarwangi 1 mengingat potensi ketersediaan buku yang ada di perpustakaan sekolah sehingga program SSR yang beberapa tahun lalu sempat dibentuk dapat dihidupkan kembali. Sedangkan SDN Mekarwangi 2, dapat memanfaatkan jarak lokasinya yang dekat dengan taman bacaan masyarakat (TBM) untuk akses buku dalam implementasi program SSR, atau dapat juga menggagas gerakan One Student One Book (OSOB) dimana setiap siswa diminta membawa satu buku bacaan dari rumah untuk dapat disimpan di kelas dan dijadikan perpustakaan kelas sehingga dalam prakteknya siswa dapat berganti-gantian saling bertukar buku sehingga variasi buku bacaan mereka terpenuhi.

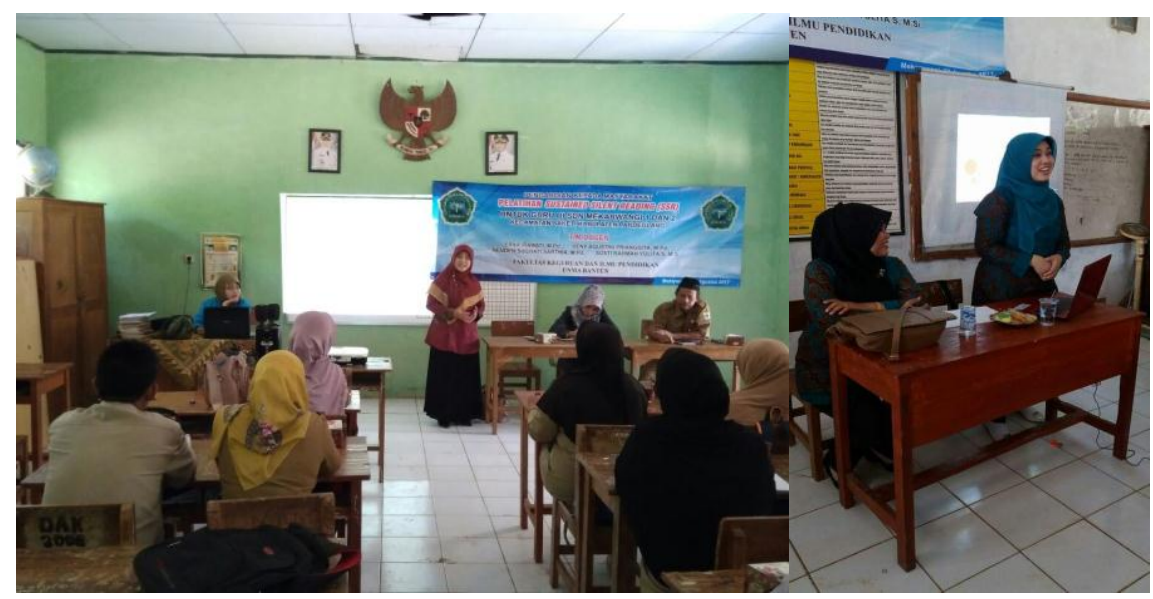

Gambar 1. Sesi 1: Penyampaian materi mengenai SSR 


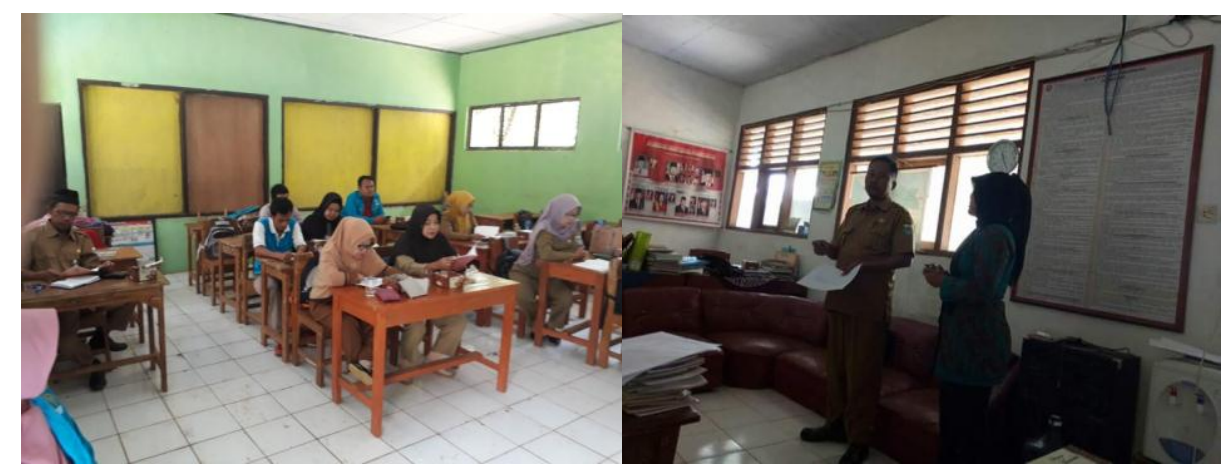

Gambar 2. Sesi 2: Praktik Program SSR

\section{SIMPULAN}

Program SSR dapat terlaksana di SDN Mekarwangi 1 dengan memanfaatkan perpustakaan yang sudah ada di sekolah, sedangkan di SDN Mekarwangi 2 program SSR dapat terlaksana setelah guru melaksanakan gerakan One Student One Book (OSOB) dimana setiap siswa diminta membawa satu buku bacaan dari rumah untuk dapat disimpan di kelas sehingga menjadi perpustakaan kelas.

Pelaksanaan SSR disesuaikan dengan kondisi siswa di SDN Mekarwangi 1 dan 2, dimana Reading Aloud disertakan untuk kelas bawah guna menjaga motivasi dan keterlibatan aktivitas membaca siswa dalam program SSR.

\section{REFERENSI}

Armadi, S., Nugroho, W., Budiatmodjo, E., Ramadani, D., \& Maylasari, I. (2016). Statistik sosial budaya 2015. Jakarta, Indonesia: Badan Pusat Statistik. url: https://microdata.bps.go.id/mikrodata/index.php/citations/295

Gardiner, S. (2005). Building students' literacy through sustained silent reading. Alexandria: Association for Supervision and Curriculum Development.

Ibda, H. (2017). Gerakan metal (membaca artikel) untuk meningkatkan kemampuan membaca kritis guru MI. MAGISTRA: Jurnal Ilmu Pendidikan Dasar dan Keislaman, 8(1), 16-43.

Inten, D. N., Permatasari, A. N., \& Mulyani, D. (2016). Literasi dini melalui teknik bernyanyi. AL-MURABBI: Jurnal Studi Kependidikan dan Keislaman, 3(1), 70-91. 
Krashen, S. (2011). Non-engagement in sustained silent reading: How extensive is it? What can it teach us?. Colorado Reading Council Journal, 22(1), 5-10.

Krashen, S. (2013). Access to books and time to read versus the common core state standards and test. English Journal: National Council of Teachers of English, 103(2), 21-29.

Kemendikbud. (2015). Permendikbud no. 23 tentang penumbuhan budi pekerti. Jakarta: Kementrian Pendidikan dan Kebudayaan.

Moser, A. M. (2006). Sustained silent reading: What could it look like in your school?. Indiana libraries, 25(1), 33-35.

Nafisah, A. (2016). Arti penting perpustakaan bagi upaya peningkatan minat baca masyarakat. LIBRARIA: Jurnal Perpustakaan, 2(2), 69-81.

Pilgreen, J. (2000). The SSR handbook: How to organize and manage a sustained silent reading program. Portsmouth: Boynton Publisher. 